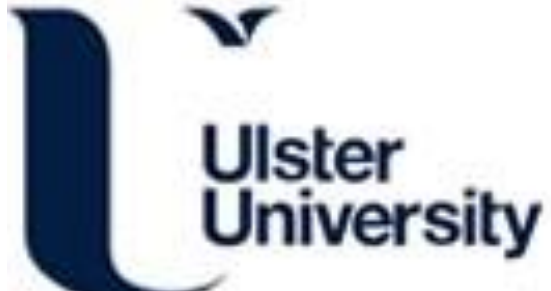

\section{Personality profiles and persuasion: An exploratory study investigating the role of the Big-5, Type D personality and the Dark Triad on susceptibility to persuasion}

Wall, H. J., Campbell, C., Kaye, L. K., Levy, A. R., \& Bhullar, N. (2019). Personality profiles and persuasion: An exploratory study investigating the role of the Big-5, Type D personality and the Dark Triad on susceptibility to persuasion. Personality and Individual Differences, 139, 69-76. https://doi.org/10.1016/j.paid.2018.11.003

Link to publication record in Ulster University Research Portal

\section{Published in:}

Personality and Individual Differences

Publication Status:

Published (in print/issue): 01/03/2019

DOI:

10.1016/j.paid.2018.11.003

\section{Document Version}

Author Accepted version

\section{General rights}

Copyright for the publications made accessible via Ulster University's Research Portal is retained by the author(s) and / or other copyright owners and it is a condition of accessing these publications that users recognise and abide by the legal requirements associated with these rights.

\section{Take down policy}

The Research Portal is Ulster University's institutional repository that provides access to Ulster's research outputs. Every effort has been made to ensure that content in the Research Portal does not infringe any person's rights, or applicable UK laws. If you discover content in the Research Portal that you believe breaches copyright or violates any law, please contact pure-support@ulster.ac.uk. 
Personality and Individual Differences

Elsevier Editorial system(tm) for

Manuscript Draft

Manuscript Number: PAID-D-18-01046R1

Title: Personality Profiles and Persuasion: An exploratory study investigating the role of the Big-5, Type D Personality and the Dark Triad on Susceptibility to Persuasion

Article Type: Full Length Article

Section/Category: Research Paper ( $<5000$ words)

Keywords: Persuasion

Types

Big5 personality

Dark Triad

Type D

Corresponding Author: Dr. helen joanne wall, Ph.D

Corresponding Author's Institution: Edge Hill University

First Author: helen joanne wall, Ph.D

Order of Authors: helen joanne wall, Ph.D; Claire Campbell, PhD Psychology; Linda K Kaye, PhD Psychology; Andy Levy, PhD Psychology; Navjot Buller, PhD Psychology

Abstract: The present study investigated the relationship between personality profiles and susceptibility to persuasion. Participants $(\mathrm{N}=$ 316) were recruited for an online questionnaire and asked to complete self-reported measures of their personality - Big-5, Dark Triad and Type D. Individual differences in susceptibility to persuasion were also explored using Cialdini's model of persuasion. Latent profile analysis identified three distinct profiles which were labelled Socially Apt, Fearful and Malevolent. These profiles were correlated with scores on the persuasion subscales - authority, commitment, liking, scarcity, reciprocity, consensus - and a number of interesting associations were identified. The malevolent profile self-reported as more susceptible to a higher use of scarcity relative to the other principles of persuasion, and were least susceptible to reciprocity and authority. The socially apt profile appear to be more inclined to be persuaded to do something if it is consistent with their beliefs or a prior act whereas individuals in the Fearful profile were more likely to report obeying those in authority and going along with a crowd. Implications for persuasion are discussed along with research on personality types. 
Dear Editor and Reviewers,

Many thanks for reviewing our paper titled: Personality Profiles and Persuasion: An exploratory study investigating the role of the Big-5, Type D Personality and the Dark Triad on Susceptibility to Persuasion. We believe that the comments were very constructive and sincerely hope that we have satisfactorily addressed all of the comments raised. We have listed each comment below in addition to how we have addressed it and look forward to hearing back from you.

Yours Sincerely

The Authors

\section{Reviewer \#1}

Reviewer Comment(s): Minor points: Highlights (for review): Highlights seem little descriptive of the study. Ex: Big-5, Dark Triad and Type D were measured. Incomplete or incorrect references: References must be in form to APA. There are references that do not include the number or volume and the name of some journals is incorrectly edited. The typeface should always be the same. It does not make sense to change the font to include the name of the journal.

Response: We have amended this section and thoroughly checked all references. We have also made the highlights more descriptive of the study and would like to thank reviewer 1 for this comment.

Reviewer Comment(s): "The interest in forming profiles using personality questionnaires and then analyzing the mean comparisons of these same questionnaires in the three profiles is not clear (Table 5 and 6). Figure 1 also makes little sense if the same personality variables have been used for the formation of the three profiles. In summary, it is a study poorly designed. The authors could analyze the three questionnaires of personality and form profiles (factors) by affinity of content using a principal component analysis. Then, these profiles could be used as dependent variables and persuasion susceptibility scales as independent. A more sophisticated design could include an analysis of structural equation models".

Response: We acknowledge the reviewer's suggestion. However, conducting a principal component analysis or another factor analysis method (which in fact is a variable-centered approach) does not answer the research aim of the present study which is to identity profiles based on three different measures of personality characteristics (Big 5, Dark Triad, and Type D). Therefore, this study presents findings based on a latent profile analysis (LPA). As noted 
in text (p.9), "identification of such typologies can provide new insights into how different personality traits combine or co-exist within an individual and how each of these personality profiles is related to persuasion. Traditional variable-centered statistical techniques examine the relationships between variables and results are at the level of variable, thus limiting our ability to form inferences about individuals... LPA specifically helps to identify specific combinations of variable scores that occur naturally within a sample and group respondents with similar scores across a set of variables."

We have now clarified in text (see p. 9) the benefits of using a LPA, which is a person-based approach, that allows us to group individuals together into probability-based profiles groupings where respondents grouped within a single profile respond similarly across the measures used. A LPA identifies different combinations of patterns of responses on a set of variables and provides a novel approach to the research area.

Table 5 provides a summary of mean differences on different personality characteristics across the 3 obtained profiles. This is a standard practice to report on these results. Figure 1 provides a visual depiction of different combinations of personality characteristics for each of the profile groping (identified as a result of LPA).

Table 6 provides the results of Multivariate Analysis of Variance (MANOVA) to examine how profile membership is associated with susceptibility to persuasion strategies. In other words, where profile differences lie on the six indices of susceptibility to persuasion strategies.

\section{Reviewer \#2:}

Reviewer Comment(s): The manuscript is written very comprehensively, using a large sample of 316 adults male and females as participants with mean age of 28.19 and SD 11.98 years. The introduction and review of researches seems to be good. The author (s) does discuss the conceptual and theoretical overlap of personality factors and persuasion and related constructs. The study aimed was to investigate the personality profile typologies exist and how are these related to susceptibility to persuasion. The methods section is very sound and authors do a good work of providing information in a concise manner. The results presented are self-explanatory and very clear to understand as it revealed that the malevolent profile as more susceptible to a higher use of scarcity relative to the other principles of persuasion and were least susceptible to reciprocity and authority. Discussion is well written and it has been critically evaluated in the light of the emerged findings. Limitations, implications and direction for future research are adequately addressed.

Response: Many thanks indeed for such a positive review of all sections of our manuscript.

\section{Reviewer \#3:}


Reviewer Comment(s): This was an interesting and topical article that reviewed a range of personality features associated with susceptibility to persuasion. The focus was predominantly on the Big-5, but also included dark-triad and type-D personality features. Whilst these latter two constructs provided some useful explanatory value in relation to the profiles which were later produced, the rationale for the inclusion of these two items in the data collection needed to be strengthened. In the Introduction, the relevance of the Dark Triad, for example, is reasonable but almost appears to be 'it has not been done before and might be relevant'. Similar criticism could be levied at the D-type. Ultimately these appear to be suitable inclusions for the study, but some more nuanced theoretical development is necessary to support the later discussion.

Response: Thank you for your positive comments. We fully agree that the justification for including Type D and the Dark Triad traits could be stronger. In response, we have added in a much stronger case for Type D and the Dark Triad (please see text highlighted in boldface bottom of page 4 and top of page 5 and second half of page 6). We believe these additions enhance the contribution of this study.

Reviewer Comment(s): The sample size is good; however, more detail is required on how the participants were recruited and exactly who they were (were additional demographics included?)

Response: Many thanks for this comment. We have clarified that the only information we obtained was in terms of participants' age and gender. We have also added more information on how the study was advertised. Please see highlighted text on page 10 .

Reviewer Comment(s): There is a large gender bias ( $80 \%$ female) which is not really expanded upon

Response: We have now added a small paragraph into the discussion highlighting this limitation and need for additional research. Please see highlighted text on page 20.

Reviewer Comment(s): Additionally, whether the sample was a convenience sample from the web or else recruited from a university class is not clear (some participants received course credit).

Response: Please see above response. We have now made clear that only information pertaining to age and gender was collected and made clear that the study was advertised to both Psychology students and the general population. As we did not collect date on how many participants comprised students we have now added this as a possible limitation and would like to thank reviewers for highlighting this point. Please see highlighted text on page 10 and discussion section page 20 .

Reviewer Comment(s): On the whole, this was a useful addition to the literature, but the inclusion of the Dark Triad/D needed to be more carefully integrated into the design and rationale as it lacks theoretical development and integration 
Response: Many thanks indeed for your positive evaluation of our manuscript and very valuable and constructive comments. 
Personality Profiles and Persuasion: An exploratory study investigating the role of the Big-5, Type D Personality and the Dark Triad on Susceptibility to Persuasion

Helen J. Wall ${ }^{1}$, Claire, C. Campbell ${ }^{2}$, Linda K. Kaye ${ }^{1}$, Andy Levy ${ }^{1}, \&$ Navjot Buller ${ }^{3}$ ${ }^{1}$ Department of Psychology, Edge Hill University, UK

${ }^{2}$ School of Psychology, Ulster University

${ }^{3}$ School of Behavioural, Cognitive and Social Sciences, University of New England, Australia

*Corresponding author: Department of Psychology, Edge Hill University, St Helen's Road, Ormskirk, L39 4QP (+44) 1695584413 helen.wall@edgehill.ac.uk 
- Big-5, Dark Triad, Type D and susceptibility to persuasion was explored

- Latent profile analysis identified three distinct profiles

- Socially Apt, Malevolent, and Fearful profiles were identified

- Profiles were related to different types of persuasion 
*Manuscript without author identities

Click here to view linked References

PERSUASIVE PERSONALITY

Personality Profiles and Persuasion: An exploratory study investigating the role of the Big-5, Type D Personality and the Dark Triad on Susceptibility to Persuasion

Keywords: Persuasion; Personality; Dark Triad; Big-5; Type-D 


\section{Introduction}

Increasing the effectiveness of interventions designed to change a person's attitude and/or behaviour is an important, but complex, endeavour. Although numerous health studies have documented the positive impact that persuasion can have (Niederdeppe, Kuang, Crock, \& Skelton, 2008; Ashford, Edmunds, \& French, 2010), the effectiveness, longevity and replicability of behaviour-change interventions has been called into question (Glasziou, Chalmers, Green, \& Michie, 2014; Prestwich, Sniehotta, Whittington, Dombrowski, Rogers, \& Michie, 2013). In response, researchers have argued for the need to adopt personalised persuasive systems (Kaptein et al., 2015; Wortman \&Wood, 2011). For example, market researchers have begun to tailor their advertising using characteristics such as gender (Yang \& Lee, 2010) and user motivation (Smith, 2011). Although such characteristics are important when tailoring advertisements it is argued here that a person's personality and personality profile is important. Indeed, it has been shown that people who are agreeable tend to be persuaded by people they like (Alkis \& Temizel, 2015) whereas people who are conscientiousness tend to be persuaded by people in authority (Alkis \& Temizel, 2015). Based on such findings, it could be argued that interventions drawing on authority figures could be targeted at individuals high in conscientiousness. However, numerous personality psychologists assert that people are more than just one trait (Chapman, Roberts, \& Duberstein, 2011; Costa \& McCrae, 1980); thus, the question of how best to persuade a person who is, for instance, high in agreeableness and low in conscientiousness requires a more nuanced approach. Accordingly, the current study explored the relationship between an individual's personality profile (Big 5, Dark Triad, and Type D) and susceptibility to persuasion strategies.

\section{Persuasion: Definition and Measurement}


Persuasive communication refers to any message that is intended to change, reinforce, or shape another person's response(s) (Cialdini, 2001; Fogg, 2002). There is much debate on what the constitution of different persuasive strategies may be, with some theorists describing 40 different "strategies" within this (Fogg, 2002) whereas others have suggested over 100 distinct tactics (Rhoads, 2007). However, the most influential model of persuasion is that of Cialdini $(2001,2004)$ who developed six principles, outlined below.

Cialdini's (2001) first principle of authority is considered a form of social influence and posits that people are inclined to follow suggestions and recommendations from a person in authority (Milgram, 1974; Blass, 1991). The second principle of consensus is asserted to operate when individuals observe multiple others displaying the same behaviour, which leads that person to behave similarly (Cialdini, 2004; Zhu \& Zhang, 2010). For example, previous research has shown that observing others disclosing information leads to increased levels of disclosure (Acquisti et al., 2012). The principle of commitment refers to the notion that people strive to maintain consistent beliefs and act in accordance with those beliefs (Cialdini, 2001). The principle of scarcity increases the perceived value of products and opportunities (Cialdini, 2001), hence the reason why many sales teams often use phrases like "last chance" and "limited stock left" to increase the likelihood of consumer purchasing behaviour (Inman et al., 1997; Eisend, 2008). Ciladini's liking principle asserts that people tend to say "yes" to people they like (Cialdini, 2001; Garner, 2005). Finally, the principle of reciprocity indicates that people tend to be inclined to return a favour (Cialdini, 2004; Greenberg, 1980).

\section{Individual Differences and Susceptibility to Persuasion}

When theorising about the constructs which may be related to susceptibility to persuasion the Big-5 personality traits (Costa \& McCrae, 1992) are ideal candidates. The Five Factor Model of personality (FFM: Costa \& McCrae, 1992) has been widely accepted as 
the dominant model for categorising individual differences in personality (Ozer \& BenetMartinez, 2006); namely these refer to the traits of extroversion, agreeableness, conscientiousness, neuroticism and openness to experience. According to this perspective, traits are relatively stable individual differences in how people think, feel and behave (Costa \& McCrae, 1992).

In support of the role of these traits on susceptibility to persuasion, a few recent studies have explored the utility of FFM traits on persuasive technologies in health-mobile applications (Halko \& Kientz, 2010; Kaptein, Markopoulos, de Ruyter, \& Aarts, 2015). Specifically, those high in agreeableness have been found to be most susceptible to Cialdini's (2001) "liking” component (Wortman \&Wood, 2011). Similarly, extraversion has also been linked to the principle of likeability (Wortman \&Wood, 2011). In relation to other components of Cialdini's model, scarcity has been found to be an effective strategy to persuade those high in neuroticism to undertake more purchasing behaviour than those low in this trait (Halevi, Lewis, \& Memon, 2013). Finally, reciprocation has been shown to be related to conscientiousness and neuroticism (Alkis \& Temizel, 2015). Taken together, it is clear that a person's personality is an important factor to study when considering which persuasion strategy to adopt.

Although the Big-5 model of personality has been well validated it has been argued that the Big5 does not capture the full range of human personality as it largely concerns the more prosocial aspects of behaviour (Paulhus \& Williams, 2002). When considering the relationship between personality and persuasion it is important to try to explore the full range of traits relevant to persuasion. The studies reviewed above documenting the relationship between the Big5 and persuasion suggest positive relationships between the Big 5 and persuasion and indicates that socially desirable traits may be associated with being persuaded. It is important to consider how traits might relate to the full range of 
responses to persuasion tactics. Put another way, what characteristics are associated with not being persuaded - or saying 'no' to others? The Dark Triad would seem an ideal framework to examine in this regard and is a term used to describe a constellation of three socially "undesirable"1 traits: psychopathy, narcissism, and Machiavellianism (Paulhus \& Williams, 2002). Psychopathy refers to a pattern of callous, remorseless manipulation and exploitation of others, and has been investigated as a psychological cause of antisocial and criminal behaviours (Hare, 1991). Narcissism has been conceptualized as a "normal" personality variable characterized by dominance, exhibitionism, and exploitation as well as feelings of superiority and entitlement (Raskin \& Terry, 1988). Machiavellianism refers to individual differences in manipulativeness, insincerity, and callousness (Christie \& Geis, 1970). Research on the Dark Triad has increased dramatically over the last decade and the traits have been described as having an exploitive social strategy (Jonason et al., 2009). Exploitation of others is different to exploitation of self and it remains open to question whether people who are high on Dark Triad traits are themselves open to the same types of manipulation and exploitation that they do to others.

Although no research has directly examined the relationship between Dark Triad traits and Cialdini's persuasion strategies, market researchers have identified the importance of these traits on purchasing behaviours. For example, consumers with narcissistic tendencies tend to prefer symbolic to utilitarian products and strive to purchase prestigious products with a view to being liked and distinguished from others (Lee, \& Seidle, 2012; Yin, Bi, \& Wan, 2016). Indeed, admiration from others is important to narcissists and they tend to have a strong need for approval and seek status in social settings (Paulhus \& Williams, 2002).

\footnotetext{
${ }^{1}$ It is important to acknowledge that some evidence has revealed positive outcomes associated with some Dark Triad traits (O’Boyle et al., 2012). Narcissists also have many positive aspects. Such as their optimistic nature with less socially anxious and depressed, their higher self-esteem status, short-term likeability, short-term successes in competitive tasks (Campbell, 2015).
} 
Therefore, associating with high-status others appears to be a good way to maintain their grandiose self-concept (Lee, \& Seidle, 2012). These relations are indicative of a link between Dark Triad traits and persuasion, particularly the authority, social proof and liking principles of Cialdini's model.

In addition to the Big-5 and Dark Triad, other traits which are conceivably relevant to persuasion is the Type-D personality (referred to as the "distressed" personality). Key characteristics found to be relevant to Type-D personality are that of avoidance of social environments for fear of rejection, and reluctance to share emotions with others, thus often having negative implications for depression and low self-esteem (Denollet, 2005). Similar to the Dark Triad, individuals who show indicators of Type-D personality may be harder to persuade. For instance, if a person tends to be pessimistic most of the time (Williams, O'Connor \& Hhoward, 2008) it is possible they are less likely to be persuaded. Also, due to experiencing feelings of depression and low self-esteem, as a result of social inhibition (AlQezweny, 2016), these are not ideal emotions to facilitate persuasion. Interestingly Shiffer, Denollet, Widderhoven, Hendricks, and Smith (2007) reported that Type D was associated with a delay in getting medication consultation in addition to poor medication adherence (Williams \& Wingate, 2012). The reported associations between high Type D personality and health behaviours suggests that people high in Type D are less likely to engage in helpful behaviours and highlights a need to identity the ways in which Type D individuals might be persuaded to engage in more productive behaviours. Moreover, DeFruyt and Denollet (2002) posit that Type D is not identical to the Big5 traits of Neuroticism and Extroversion. Social inhibition, for example, refers to insecurity and withdrawal in addition to the pervasive individual differences in noexpression. This global trait, although closely related to the interpersonal dimension of extroversion is not closely related to the intrapsychic dimension of extroversion (i.e. 
positive affect, energy, excitement seeking) (Denollet, 1981). Accordingly, we explore this as a final factor in our research to better capture the range of correlates from which to develop personality profiles and their association with susceptibility to persuasion.

\section{Going beyond bivariate associations: the need for a profile approach}

Currently most persuasive approaches described in the literature or implemented commercially are not personalizing their "ways" or if they are it is based on single characteristics such as gender, motivation or age (Smith, 2011; Yang \& Lee, 2010), which although useful, cannot fully capture differences in emotion, cognition and social/antisocial behaviour that form part of the Big-5, Dark Triad and Type D personality traits.

Furthermore, relying on one characteristic associated with persuasion strategies can backfire. In support of this claim, Mols et al. (2015) propose that young people, once aware of the persuasive manipulation, could become reactive and try to 'defy the system'. In addition, Fuegen and Brehm (2004) reported how authority endorsements can lead to negative effects when people's perception of freedom of choice is threatened. Taken together, it is clear that persuasive communications can have different effects for different people and that 'one approach fits all' may not always be the most effective approach. It is evident that single level characteristics such as extroversion or narcissism have been examined and it is argued here that to increase the longevity and replicability of persuasive communication it is important to explore the personality profile associated with the different persuasion strategies.

Moreover, in relation to the present exploration of individual differences in susceptibility to persuasion, it is imperative to draw on research that has investigated whether people can be clustered empirically into distinct prototypical personality types. Evidence from numerous studies shows that the five personality traits can be clustered into three personality types, known as resilient, undercontrolled, and overcontrolled (RUO) (Asendorpf, 
Borkenau, Ostendorf, \& Van Aken, 2001; Asendorpf \& van Aken, 1999; Robins, John, Caspi, Moffitt, \& Stouthamer- Loeber, 1996). The resilient- type of person appears to be someone one with a lower than average Neuroticism score and higher than average values in the remaining Big 5 traits. The Overcontrolled type has been found to show the opposite pattern and the undercontrolled type appears to have lower than average Conscientiousness and Agreeableness and higher than average Openness, Extraversion, and Neuroticism. Although these types have been replicated in several different linguistic and cultural traditions (e.g. Alessandri et al., 2014; Klimstra, Hale, Raaijmakers, Branje, \& Meeus, 2010) there appears to be inconsistencies in terms of how robust they are (see Asendorpf, 2002 for a discussion on failed replications). Moreover, recent researchers have found that other prototypes have emerged from diff erent cluster research: for example, the confident type was marked by high Openness and Extraversion scores (Herzberg \& Roth, 2006). Although numerous studies describing personality types have relied on the FFM a growing number of researchers are calling for studies to go beyond the simple replication of these classic three types by identifying new personality types (e.g., De Fruyt, Mervielde, \& van Leeuwen, 2002). In response, a recent study by Sârbescu and Boncu (2018; see Herzberg \& Roth, 2006) explored types using the Alternative Five-Factor Model (AFFM) and although they found some replication of the classic (RUO) types they did find some differences whereby their 'strain type' did not match the under controlled type. Taken together, this evidence suggests that there is more to uncover about personality types and that further exploration into how types might correlate with key outcomes is warranted. Accordingly, the present study goes beyond the Big 5 and incorporates a range of traits theorised to be related to persuasion (i.e., the Big 5, Dark Triad, and Type D).

\section{The Present Study}


To date, no empirical research has examined profile-based combinations of the Big 5, the Dark Triad, and Type-D personality traits and their association with susceptibility to persuasion. Identification of such typologies can provide new insights into how different personality traits combine or co-exist within an individual and how each of these personality profiles is related to persuasion. Traditional variable-centered statistical techniques examine the relationships between variables and results are at the level of variable, thus limiting our ability to form inferences about individuals (Holloway, Bhullar, \& Schutte, 2017). For example, a standard regression approach explores the main effects in addition to any interactions, but it does not guarantee that the implied "groups" (with high scores on one variable and low on another) obtained in a moderation analysis are always meaningful.

However, person-centered approaches, such as a latent profile analysis (LPA) classifies individuals into homogenous probability-based groupings and examines the relationships between individuals and their different patterns of responses (Collins \& Lanza, 2009). LPA specifically helps to identify specific combinations of variable scores that occur naturally within a sample and allows us to group individuals together into probability-

\section{based profile groupings where respondents grouped within a single profile respond} similarly across the measures used. We do not expect linear relationships between different personality characteristics (the Big 5, Dark Triad, and Type D), therefore, LPA provides a novel approach to examine the prevalence of different patterns of responses on a range of individual difference variables (Bhullar, Rickwood, Carter \& Haridas, 2017; Haridas, Bhullar, \& Dunstan, 2017; Holloway et al., 2017). Accordingly, we adopted this approach and operationalised it through formulating the following research question:

1. What personality profile typologies exist and how are these related to susceptibility to persuasion?

\section{METHOD}




\section{Participants and Procedure}

Participants $(N=316$; mean age $=28.19 ; S D=11.98$; women $=82 \%)$ were recruited for an online questionnaire via a study link, which was advertised through Social Networking Sites (SNSs), including Twitter. The study link was also advertised to Psychology students thus the sample comprises participants from the general population and Psychology students. The online questionnaire was advertised as a study exploring "Personality and Persuasion". Once people clicked on the link they were directed to additional information about the study outlining that the study was investigating the relationship between personality traits and behaviour; more specifically, whether behaviour is influenced by self or others. Incentives for participation included the opportunity for participants to enter a prize draw to win $£ 50$ in Amazon Vouchers as remuneration, or course credit. The study link contained an overview of the purpose of the research and participants' ethical rights, followed by demographic questions pertaining to age and gender.

\section{Measures}

The Big-5 Personality.

Participants were asked to complete a self-report measure of their Big-5 personality using the 50-item International Personality Item Pool (IPIP-Big-5, Goldberg et al., 2006). This widely used measure (e.g., Ashton \& Lee, 2005; Christiansen, Wolcott-Burnam, Janovics, Burns, \& Quirk, 2005) demonstrates good construct validity (Buchanan, Johnson, \& Goldberg, 2005) as it has been shown to correlate highly with corresponding scores on Costa and McCrae's $(1985,1989)$ Revised NEO Personality Inventory measuring Neuroticism, Extroversion and Openness (NEO-PI-R) (International Personality Item Pool, 2011). The measure comprises 50-items; 10 items per sub-scale of extraversion, neuroticism, 
conscientiousness, openness, and agreeableness. For each item, participants were asked to rate the extent to which the statement described themselves, on a 7-point scale, ranging from 1 (Extremely Inaccurate) to 7 (Extremely Accurate). This measure demonstrated good reliability in the present sample (extroversion $\alpha=.90$; agreeableness $\alpha=.85$; conscientiousness $\alpha=.81$; neuroticism $\alpha=.90$; and openness to experience $\alpha=79$ ).

\section{Dark Triad Traits.}

The three traits of Narcissism, Machiavellianism, and Psychoticism were measured using the 12-item 'Dirty Dozen' measure (Jonason \& Webster, 2010). A response scale from 1 (strongly disagree) to 7 (strongly agree) was used. Four items measured each trait in the triad. An example item for Narcissism is 'I tend to want others to admire me', an example item for Psychopathy is, 'I tend to lack remorse' and an example item for Machiavellianism is 'I tend to manipulate others to get my way'. Although this measure is relatively new it has demonstrated good psychometric properties (Jonason \& Webster, 2010). Reliability coefficients for the present study were also good (narcissism $\alpha=.81$; psychopathy $\alpha=.73$; machiavellianism $=.80$ ).

\section{Type-D.}

The Type-D Scale-14 (DS14; Denollet, 2005) was used in the present study. This is a 14-item multidimensional measure of Type-D trait personality. The DS14 assess the two global traits of social inhibition (SI, 7 items) and negative affectivity (NA, 7 items), and Type-D personality. It uses a 5-point Likert-type scale anchored at $0=$ false to $4=$ true. The questionnaire allows the scoring of SI and NA as continuous variables (range, 0-28) or TypeD. A score of 10 or above on both SI and NA subscales of the DS14 indicates the presence of Type-D personality.). Good psychometric properties have been reported for the DS14. Denollet (2005) reported good internal consistency ( $\alpha=.86$ and .88 for SI and NA, respectively), test-retest reliability ( $r=.82$ and.72 for SI and NA and SI) and factorial 
structure. This measure demonstrated good reliability for SI ad NA in the present sample $(\alpha=$ $.88 ; \alpha=.90$, respectively).

\section{Susceptibility to Persuasion}

The Susceptibility to Persuasion Scale (STPS; Kaptein, 2012) is a 28-item questionnaire which measures the degree of propensity for being influenced by the six strategies of persuasion in Ciladini's model, namely scarcity, liking, reciprocation, commitment, consensus, and authority. The items were rated on a 7-point scale from 1 (completely disagree) to 7 (completely agree). The measure has demonstrated good psychometric properties (Alkış, \& Temizel, 2015). Reliability coefficients for the present study were also good $\left(\alpha_{\text {scarcity }}=.60 ; \alpha_{\text {liking }}=.64 ; \alpha_{\text {reciprocation }}=.80 ; \alpha_{\text {commitment }}=.77 ;\right.$ consensus $\alpha_{\text {consensus }}=.70 ;$ and $\alpha_{\text {authority }}=.80$ ).

\subsection{Statistical Analyses}

A LPA using Mplus (v.7.3) (Muthén \& Muthén, 1998-2012) was conducted to classify respondents based on shared pattern of their responses on a range of personality characteristics (Big 5, Dark Triad, and Type D). LPA is considered a sophisticated analytical tool used to assess how unique combinations of continuous latent variables and underlying categorical latent variables cluster within homogeneous groupings within a sample. Several model fit indices were assessed to determine the optimal profile model, including the Bayesian Information Criteria (BIC), which assesses improvement in fit after adjusting for the number of parameters in a model, sample size adjusted BIC (Schwarz, 1978; Sclove, 1987), Vuong-Lo-Mendel-Rubin (VLMR) Adjusted test, and the Bootstrapped Likelihood Ratio test (BLRT). The VLMR and BLRT assess difference in goodness-of-fit between model $k$ and model $k$ - 1 , where $k$ refers to the number of retained profiles. The preferred model is indicated by a combination of smallest BIC and adjusted BIC values with highest number of profiles, and significant $p$ values for LMR and BLRT indicate best fit, i.e., model 
$k$-1 should be rejected in favor of model $k$ (Muthén \& Muthén, 1998-2010). Entropy was also used as an index of model assessment, with values close to one considered ideal (Ostrander, Herman, Sikorski, Mascendaro, \& Lambert, 2008). In addition to statistical adequacy, we also considered theoretical conformity and meaningfulness and interpretability of the preferred profile-solution to guide our decision regarding retaining the number of profiles (Bauer \& Curran, 2003; Marsh, Lüdtke, Trautwein, \& Morin, 2009; Muthén, 2003).

To facilitate interpretation of profiles, we standardized all 10 profiling variables to a mean of 0 with a standard deviation of 1 . Two multivariate analyses of variance (MANOVAs) were conducted to determine significant profile differences in different personality traits (used as profiling variables) and susceptibility to persuasion strategies, respectively.

\section{RESULTS}

\section{Descriptive Statistics}

All missing data $(0.2 \%)$ were imputed using the expectation maximization technique in SPSS v.24. Table 1 shows intercorrelations, means, and standard deviations of key study variables. Agreeableness and conscientiousness were significantly associated with greater reciprocation, commitment, and authority. Neuroticism was significantly associated with greater scarcity, liking, consensus and authority. Openness was related to greater commitment and less consensus and authority. Machiavellianism was related to less reciprocation, commitment, and authority and greater consensus. Narcissism and Psychopathy were associated with greater scarcity and liking, and less reciprocation and commitment, respectively. Neuroticism was also related to greater consensus whereas Psychopathy was related to less authority. Both Social inhibition and Negative affectivity were associated with 
greater consensus and less commitment. Negative affectivity was also related to greater scarcity and liking.

\section{[Insert Table 1 about here].}

Table 2 presents bivariate correlations between personality variables. As expected, the Big 5 personality variables were significantly associated with each other. However, there were so significant associations between Extraversion and Conscientiousness and between Neuroticism and Agreeableness, and Openness. The Big 5 variables were also significantly related with Dark Triad in the expected direction. However, Extraversion and Neuroticism were not significantly associated with Psychopathy, with Neuroticism also not significantly related to Machiavellianism. The Dark Triad variables were significantly related to each other and with greater negative affectivity subscale of Type D. Psychopathy was also significantly related with greater Social inhibition subscale of Type D. Greater Social inhibition was also related with Negative affectivity.

\section{[Insert Table 2 about here].}

Table 3 presents bivariate correlations between six persuasion strategies. All persuasion strategies were significantly related in the expected direction, with an exception of no significant relationship between commitment and consensus strategies.

\section{[Insert Table 3 about here].}

\section{Latent Profile Analysis}

A LPA investigated profiles based on combinations of the Big 5 (Extraversion, Agreeableness, Conscientiousness, Neuroticism, and Openness of experience), Dark Triad traits (Machiavellianism, Narcissism and Psychopathy), and Type-D (Social inhibition and Negative affectivity) personality traits. Table 4 provides a summary of various model fit indices for 2- through 5-profile solutions. 


\section{[Insert Table 4 about here].}

Results revealed that the 3-profile solution met the criteria for all the relevant fit indices. In addition to the statistical adequacy, our preferred profile solution also demonstrated practical meaningfulness of the profiles. Therefore, we interpreted the 3-profile solution in the present study. Figure 1 shows the standardised mean scores of the profiling personality variables (the Big 5, Dark Triad and Type D). Profile 1 ( $n=68,21.8 \%$ of the sample), labelled as "Malevolent" comprised individuals who reported greater Dark Triad traits, and above average scores on Extraversion and Negative affectivity subscale of Type D and average standardised scores on Neuroticism, Openness, and Social inhibition. Profile 2 ( $n$ $=148,47.4 \%)$, labelled as "Socially Apt", was the largest group in the study comprising individuals who reported above average standardised scores on Extraversion, Agreeableness, and Consciousness and average score on Openness, and lower scores on Neuroticism, Dark Triad and Type D traits. Finally, respondents in Profile $3(n=96,30.8 \%)$, labelled as "Fearful", reported higher levels of Neuroticism, Social inhibition and Negative affectivity, lower levels of Extraversion, and average scores on Agreeableness, Conscientiousness, Openness, Machiavellianism, Narcissism, and Psychopathy.

\section{[Insert Figure 1 about here].}

One-way MANOVA found significant profile differences in the profiling personality variables, $F(20,600)=48.04, p<.001$; Wilk's $\lambda=.15$; partial $\eta^{2}=.62$, a large effect size. Post-hoc comparisons, summarised in Table 5, revealed that individuals in Profile 1 reported significantly higher scores on Machiavellianism, Narcissism and Psychopathy than that of Profiles 2 and 3. In contrast, Profile 2 reported significantly higher scores on Extraversion, Agreeableness, and Conscientiousness as compared with Profiles 1 and 3. Relative to other profile groups, Profile 3 reported significantly higher scores on Neuroticism, Social inhibition and Negative affectivity. Respondents in Profiles 2 and 3 did not significantly differ on 
Machiavellianism and Narcissism. Finally, members of the three profiles did not significantly differ on Openness to experience.

\section{Profile Differences in Susceptibility to Persuasion}

We conducted a second one-way MANOVA to examine whether profile membership was associated with susceptibility to persuasion. Results revealed a significant association, $F(12,608)=5.92, p<.001$, Wilk's $\lambda=.80 ;$ partial $\eta^{2}=.11$, a medium effect size. Post-hoc comparisons, summarised in Table 6, indicated that respondents in Profile 1 reported significantly greater susceptibility to scarcity persuasion strategy as compared with Profile 2, which did not differ significantly from Profile 3. Relative to other two profiles, Profile 1 reported significantly less susceptibility to three persuasion strategies of reciprocity, commitment, and authority. Profile 2 reported significantly greater susceptibility to commitment persuasion strategy as compared with Profile 3. There were no significant differences between Profiles 2 and 3 on scarcity, reciprocity, consensus, and authority. Finally, there were no significant profile differences in liking persuasion strategy. 


\section{DISCUSSION}

The current study aimed to extend existing literature on person-centred persuasion by operationalising profile analysis as a means of establishing combinations of traits which form distinct profiles and how these may be related to different persuasion principles. As such, this presents a novel approach within the personality-persuasion literature and highlights the utility of looking beyond variable-level analysis in areas of personality enquiry. The main findings and implications are discussed below.

LPA revealed three distinct profile typologies, namely; the first profile arguably captures more malevolent characteristics as respondents comprising Profile 1 exhibited high scores on all dark triad traits with above average scores on extraversion and negative affectivity. Importantly, this profile was more susceptible to a higher use of scarcity relative to the other principles of persuasion, and was least susceptible to reciprocity and authority. Accordingly, this profile was labelled "Malevolent" and appears to be less willing to obey authority and less willing to return a favour but more likely to be persuaded to do something via the scarcity strategy. This pattern of findings is in line with definitions of the Dark Triad traits as socially aversive (Paulhus \& Williams, 2002). Individuals high in Dark Triad traits have been shown to exploit others and act in selfish ways (Jonason \& Webster, 2012; Jones, 2013) which fits with the present findings for the scarcity persuasion strategy. Put another way, those high in Dark Triad traits are more likely to purchase something for themselves or do something if they think that they have a limited time frame within which to do it. The current findings also suggest that this profile is less likely to be persuaded by strategies that involve doing things for others such as reciprocity or obeying an authority figure.

Interestingly, those high in Dark Triad traits are described as being manipulative and have been shown to be able to influence others (Jonason \& Webster, 2012; Paulhus \& Williams, 2002), thus an interesting question that the present study sought to explore was whether those 
high in Dark Triad traits can themselves be influenced by others? ? These exploratory findings suggest that this profile are less likely to be persuaded by the more 'other-oriented' persuasion strategies such as 'reciprocation' and 'authority'.

The second profile was labelled "Socially apt" as respondents in this grouping reported significantly higher scores on extraversion, agreeableness and conscientiousness and had average scores on openness compared with other two profiles. Our findings suggest that this profile was more susceptible to the commitment persuasion strategy and was no different from Profile 3 on the scarcity, reciprocity, consensus and authority strategies of persuasion. Profile 2 largely differed for one strategy, commitment. Recall that the persuasion strategy of commitment refers to the notion that people strive to maintain consistent beliefs and act in accordance with those beliefs (Cialdini, 2001); thus, the findings suggest that individuals who are "socially apt" are more inclined to be persuaded to do something if it is consistent with their beliefs or a prior act.

The third profile, labelled "Fearful" comprised individuals who scored significantly higher on neuroticism, social inhibition and negative affectivity and scored very low on extraversion as compared with other profile groups. In terms of how this profile related to the persuasion subscales, results found that individuals comprising this profile were more susceptible to the commitment strategy (compared with Profiles 1) and lower than Profile 2. Profile 3 was found to be higher on consensus persuasion strategy than Profile 2 and higher on authority compared with Profile 1 . Thus, in contrast to the Malevolent profile, individuals in Fearful profile grouping were more likely to report obeying those in authority, going along with a crowd, and following through with an act once they have committed to it. Interestingly, this profile contained high Type D scores, known as the "distressed personality" (i.e., high negative affectivity and social inhibition) and the pattern of findings suggests that this profile of traits appear to be more susceptible to the more 'other-oriented' 
persuasion strategies of reciprocity, consensus and commitment but not the scarcity strategy. Interestingly, these findings are arguably in line with literature documenting the fear of social disapproval that those high in Type D fear. In support, research on social inhibition, one of the facets of Type D, has been shown to be related to the avoidance of disapproval from others or non-reward by others in social interaction (Dennolet, 2005).

Given the exploratory nature of this novel study further research is needed in order to determine if the present findings can be replicated. It will also be interesting to investigate whether the profiles obtained in the present study can predict behavioural outcomes such as attitude change on the basis of employing some of Cialdini's persuasion strategies measured here. As noted by Vohs, Baumeister, and Funder (2007), it is important to obtain behavioural measures in addition to self-reported data. The findings hold potential for research into the efficacy of personalised persuasive interventions. For example, it remains an open question whether tailoring interventions to the personality profiles obtained in the present study using Cialdini's persuasion strategies actually leads to more effective attitude and/or behaviour change compared to non-personalised approaches or approaches that only target one aspect of a person's personality such as the trait of agreeableness. Our findings suggest that Fearful profile is more likely to be persuaded by persuasion tactics such as reciprocity whereas the more Malevolent profiles are more likely to be persuaded by scarcity tactics and represent an exciting area of inquiry for the interrelated fields of personality, social and consumer psychology.

It is important to compare, at a descriptive level, the present findings to the existing body of research on types that has focused predominantly on the Big5 (see Figure 1). The "socially apt" profile bears some similarities with the "resilient" type as we found that individuals in this study also tended to have low scores on neuroticism and higher scores in all other Big5 traits. However, in comparison to the "resilient" type identified in previous 
work we did not find high openness scores and instead found that this profile was characterised by low openness. Interestingly, we also found that the socially apt individual was low in DT traits. In comparison, the "fearful" profile identified in this study bears some resemblance to the "over-controlled" profile as individuals scored high in neuroticism and low on the other Big-5 traits; however, we also found low DT scores and high levels of SI and NA scores hence our label of "fearful". Our final profile of "malevolent" bears less resemblance to the "under controlled" profile as although we also found low levels of agreeableness and conscientiousness we did not find high levels of openness, extroversion and neuroticism and we also found high levels of DT traits. Thus, although there were some overlaps there appear to be some interesting differences that warrant further exploration and replication.

As with all research, the present study is not without its limitations. First, the present study used self-report measures, which are susceptible to social desirability; and, the use of a cross-sectional design limits any causal inferences about the obtained effects. We also acknowledge that the profiles identified in the present study might not reflect existing subgroupings within the actual population (Bauer \& Curran, 2004). To address this, future studies could employ longitudinal designs to track personality profile trajectories over time. Future research might also replicate the present findings with different age and population groups, especially the use of a clinical sample is recommended.

Another potential limitation is the composition of the participants as they were largely females $(80 \%)$. Given that some research has documented gender differences in persuasion in online contexts (Guadagno \& Cialdini, 2002) it would appear prudent to conduct additional research with more equal numbers of male and female students before firm conclusions can be drawn. Unfortunately, we did not obtain data on how many participants were students and how many were members of the general 
community; therefore, it is important to determine whether the present findings generalise to other samples.

Overall, our findings contribute a novel approach to the personality psychology literature, specifically in relation to how it correlates with susceptibility to persuasion. We advocate the efficacy of a profile approach in this area of research, and encourage further research which operationalises this perspective to move beyond a variable-level approach, so as to capture the multi-dimensionality of an individual's trait combinations and its impact on behaviour. 


\section{REFERENCES}

Acquisti, A., John, L. K., \& Loewenstein, G. (2012). The impact of relative standards on the propensity to disclose. Journal of Marketing Research, 49(2), 160-174.

Alkış, N., \& Temizel, T. T. (2015). The impact of individual differences on influence strategies. Personality and Individual Differences, 87, 147-152

American Psychiatric Association. (1994). DSM-IV® Sourcebook (Vol. 1). American Psychiatric Pub.

Ashford, S., Edmunds, J., \& French, D. P. (2010). What is the best way to change self efficacy to promote lifestyle and recreational physical activity? A systematic review with meta analysis. British journal of health psychology, 15(2), 265-288.

Bauer, D. J., \& Curran, P. J. (2004). The integration of continuous and discrete latent latent variable models: Potential problems and promising opportunities. Psychological Methods, 9, 3-29.

Baumeister, R. F., Vohs, K. D., \& Funder, D. C. (2007). Psychology as the science of selfreports and finger movements: Whatever happened to actual behavior? Perspectives on Psychological Science, 2(4), 396-403.

Bhullar, N., Rickwood, D., Carter, T., \& Haridas, S. (2017). Taking care of teenagers, taking care of me: Profiling parental caregiving burden and activity restriction in a sample of Australian parents. International Journal of Mental Health Nursing, 26, 593-601 doi: 10.1111/inm.12285

Blass, T. (1991). Understanding behavior in the Milgram obedience experiment: The role of personality, situations, and their interactions. Journal of personality and social psychology, 60(3), 398.

Campbell, W. K. (2001). Is narcissism really so bad?. Psychological Inquiry, 12(4), 214-216. 
Chapman, B. P., Roberts, B., \& Duberstein, P. (2011). Personality and longevity: knowns, unknowns, and implications for public health and personalized medicine. Journal of aging research, 2011.

Christie, R., \& Geis, F. (1970). The ten dollar game. Studies in Machiavellianism, 161-172.

Cialdini, R. B. (2001). The science of persuasion. Scientific American, 284(2), 76-81.

Cialdini, R. B. (2004). The science of persuasion. Scientific American Mind, 14(1), 70-77.

Collins, L. M., \& Lanza, S. T. (2009). Latent class and latent transition analysis: With applications in the social, behavioral, and health sciences. Hoboken, NJ: Wiley.

Costa, P. T., \& McCrae, R. R. (1980). Influence of extraversion and neuroticism on subjective wellbeing: happy and unhappy people. Journal of personality and social psychology, 38(4), 668.

Costa Jr, P. T., \& McCrae, R. R. (1992). Four ways five factors are basic. Personality and individual differences, 13(6), 653-665.

Denollet, J. (2005). DS14: standard assessment of negative affectivity, social inhibition, and Type D personality. Psychosomatic medicine, 67(1), 89-97

Deutsch, M., \& Gerard, H. B. (1955). A study of normative and informational social influences upon individual judgment. The journal of abnormal and social psychology, 51(3), 629.

Dijkstra, A. (2008). The psychology of tailoring- ingredients in computer- tailored persuasion. Social and personality psychology compass, 2(2), 765-784.

Prestwich, A., Sniehotta, F. F., Whittington, C., Dombrowski, S. U., Rogers, L., \& Michie, S. (2014). Does theory influence the effectiveness of health behavior interventions? Meta analysis. Health Psychology, 33(5), 465.

Eisend, M. (2008). Explaining the impact of scarcity appeals in advertising: The mediating role of perceptions of susceptibility. Journal of Advertising, 37(3), 33-40. 
Fogg, B. J. (2002). Persuasive technology: using computers to change what we think and do. Ubiquity, 2002(December), 5 .

Fuegen, K., \& Brehm, J. W. (2004). The intensity of affect and resistance to social influence. Resistance and persuasion, 39-63.

Garner, J. P. (2005). Stereotypies and other abnormal repetitive behaviors: potential impact on validity, reliability, and replicability of scientific outcomes. ILAR journal, 46(2), 106-117.

Glasziou, P. P., Chalmers, I., Green, S., \& Michie, S. (2014). Intervention synthesis: a missing link between a systematic review and practical treatment (s). PLoS Medicine, 11(8), e1001690.Prestwich, Sniehotta, Whittington,

Greenberg, J. (1983). Overcoming egocentric bias in perceived fairness through self awareness. Social Psychology Quarterly, 152-156.

Halevi, T., Lewis, J., \& Memon, N. (2013, May). A pilot study of cyber security and privacy related behavior and personality traits. In Proceedings of the 22nd International Conference on World Wide Web (pp. 737-744). ACM.

Halko, S., \& Kientz, J. A. (2010, June). Personality and persuasive technology: an exploratory study on health-promoting mobile applications. In International conference on persuasive technology (pp. 150-161). Springer, Berlin, Heidelberg.

Hare, R. D. (1991). The Hare psychopathy checklist-revised: Manual. Multi-Health Systems, Incorporated.

Haridas, S., Bhullar, N., \& Dunstan, D.A. (2017). What's in character strengths? Profiling strengths of the heart and mind in a community sample. Personality and Individual Differences, 113, 32-37.

Holloway, K., Bhullar, N., \& Schutte, N.S. (2017). A latent profile analysis of dispositional hope and defense styles. Personality and Individual Differences, 114, 151-154. 
James, J. M., \& Bolstein, R. (1990). The effect of monetary incentives and follow-up mailings onthe response rate and response quality in mail surveys. Public opinion quarterly, 54(3), 346361.

James, J. M., \& Bolstein, R. (1990). The effect of monetary incentives and follow-up mailings on the response rate and response quality in mail surveys. Public opinion quarterly, 54(3), 346-361.

Jonason, P. K., Li, N. P., Webster, G. D., \& Schmitt, D. P. (2009). The dark triad: Facilitating a short- term mating strategy in men. European Journal of Personality, 23(1), 5-18.

Kaptein, M., Markopoulos, P., De Ruyter, B., \& Aarts, E. (2015). Personalizing persuasive technologies: Explicit and implicit personalization using persuasion profiles. International Journal of Human-Computer Studies, 77, 38-51.

Kreuter, M. W., \& Strecher, V. J. (1996). Do tailored behavior change messages enhance the effectiveness of health risk appraisal? Results from a randomized trial. Health Education Research, 11(1), 97-105.

Lee, S. Y., \& Seidle, R. (2012). Narcissists as consumers: The effects of perceived scarcity on processing of product information. Social Behavior and Personality: an international journal, 40(9), 1485-1499.

Lynn, M. (1989). Criticisms of an evolutionary hypothesis about race differences: A rebuttal to Rushton's reply. Journal of Research in Personality, 23(1), 21-34.

Herkenham, M., Lynn, A. B., Johnson, M. R., Melvin, L. S., de Costa, B. R., \& Rice, K. C. (1991). Characterization and localization of cannabinoid receptors in rat brain: a quantitative in vitro autoradiographic study. Journal of Neuroscience, 11(2), 563-583.

Marsh, H. W., Lüdtke, O., Trautwein, U., \& Morin, A. J. (2009). Classical latent profile analysis of academic self-concept dimensions: Synergy of person-and variable- centered approaches to theoretical models of self-concept. Structural Equation Modeling, 16, 191-225. 
Milgram, S., \& van Gasteren, L. (1974). Das Milgram-Experiment. ) Rowohlt.

Mols, F., Haslam, S. A., Jetten, J., \& Steffens, N. K. (2015). Why a nudge is not enough: A social identity critique of governance by stealth. European Journal of Political Research, 54(1), 81-98.

Massar, K., \& Buunk, A. P. (2013). Gender differences in adolescent advertising response: The role of involvement and message claim. Psychology, 4(07), 547.

Muthén, B. (2003). Statistical and substantive checking in growth mixture modeling: Comment on Bauer and Curran (2003). Psychological Methods, 8, 369-377.

Muthén, L.K., \& Muthén, B.O. (1998-2012). Mplus User's Guide. (7 ${ }^{\text {th }}$ ed.). Los Angeles, CA: Muthén \& Muthén.

Niederdeppe, J., Kuang, X., Crock, B., \& Skelton, A. (2008). Media campaigns to promote smoking cessation among socioeconomically disadvantaged populations: what do we know, what do we need to learn, and what should we do now?. Social science \& medicine, 67(9), 1343-1355.

O'Boyle Jr., Ernest H.,Forsyth, Donelson R.,Banks, George C.,McDaniel, Michael A. (2012). A metaanalysis of the Dark Triad and work behavior: A social exchange perspective. Journal of Applied Psychology, Vol 97(3), 557-579

Ostrander, R., Herman, K., Sikorski, J., Mascendaro, P., \& Lambert, S. (2008). Patterns of psychopathology in children with ADHD: A latent profile analysis. Journal of Clinical Child \& Adolescent Psychology, 37, 833-847.

Ozer, D. J., \& Benet-Martinez, V. (2006). Personality and the prediction of consequential outcomes. Annu. Rev. Psychol., 57, 401-421.

Paulhus, D. L., \& Williams, K. M. (2002). The dark triad of personality: Narcissism, Machiavellianism, and psychopathy. Journal of research in personality, 36(6), 556 
Raskin, R., \& Terry, H. (1988). A principal-components analysis of the Narcissistic Personality Inventory and further evidence of its construct validity. Journal of personality and social psychology, 54(5), 890.

Schwarz, G. (1978). Estimating the dimension of a model. The Annals of Statistics, 6, 461-464.

Sclove, S. L. (1987). Application of model-selection criteria to some problems in multivariate analysis. Psychometrika, 52(3), 333-343.

Sclove, S. L. (1987). Application of model-selection criteria to some problems in multivariate analysis. Psychometrika, 52, 333-343.

Strecher, V. J., Kreuter, M., Den Boer, D. J., Kobrin, S., Hospers, H. J., \& Skinner, C. S. (1994). The effects of computer-tailored smoking cessation messages in family practice settings. Journal of Family Practice, 39(3), 262-270.

Webb, T. L., \& Sheeran, P. (2006). Does changing behavioral intentions engender behaviour change? A meta-analysis of the experimental evidence. Psychological bulletin, 132(2), 249.

Wolin, L. D. (2003). Gender issues in advertising_An oversight synthesis of research: 1970 2002. Journal of advertising research, 43(1), 111-129.

Wortman, J., \& Wood, D. (2011). The personality traits of liked people. Journal of Research in Personality, 45(6), 519-528.

Yin, C. Y., Bi, N., \& Wan, Y. (2016, May). Narcissistic Consumers' Response to Self focused Appeal Online Advertising: Evidence from Chinese Gen Y. In WHICEB (p. 39).

Zhu, F., \& Zhang, X. (2010). Impact of online consumer reviews on sales: The moderating role of product and consumer characteristics. Journal of marketing, 74(2), 133-148. 
Table 1

Means, Standard Deviations (SD) and Bivariate Correlations between Personality and Susceptibility to Persuasion Variables

\begin{tabular}{|c|c|c|c|c|c|c|c|c|}
\hline \multirow[t]{2}{*}{ Personality Variables } & \multicolumn{7}{|c|}{ Susceptibility to Persuasion Subscales } & \multirow[b]{2}{*}{$S D$} \\
\hline & Scarcity & Liking & Reciprocation & Commitment & Consensus & Authority & $M$ & \\
\hline 1. Extraversion & .06 & -.04 & .01 & .06 & $-.16^{*}$ & $-.11^{*}$ & 41.21 & 11.28 \\
\hline 2. Agreeableness & .07 & .17 & $.45^{* * *}$ & $.42^{* * *}$ & .08 & $.22^{* *}$ & 54.54 & 8.90 \\
\hline 3.Conscientiousness & .02 & .01 & $.23^{*}$ & $.52^{* * *}$ & -.11 & $.17^{*}$ & 46.97 & 8.98 \\
\hline 4. Neuroticism & $.17^{* *}$ & $.24^{* * *}$ & .08 & .01 & $.41^{* * * *}$ & $.17^{*}$ & 43.62 & 11.70 \\
\hline 7. Narcissism & $.26^{* *}$ & $.19^{* * *}$ & $-.15^{* *}$ & $-.15^{* *}$ & $.18^{* *}$ & -.10 & 13.17 & 5.45 \\
\hline 8. Psychopathy & $.20^{* *}$ & $.14^{* *}$ & $-.28^{* *}$ & $-.37^{* *}$ & -.05 & $-.27^{* *}$ & 10.19 & 4.75 \\
\hline
\end{tabular}




\begin{tabular}{|c|c|c|c|c|c|c|c|c|}
\hline 9. Social inhibition & .01 & .05 & -.08 & $-.14^{* *}$ & $.20^{* *}$ & .09 & 12.23 & 6.50 \\
\hline 10. Negative affectivity & $.17^{* *}$ & $.15^{* *}$ & -.02 & $-.12^{*}$ & $.36^{* * * *}$ & .08 & 12.96 & 6.67 \\
\hline$M$ & 21.96 & 18.65 & 26.73 & 16.41 & 16.91 & 23.19 & - & - \\
\hline$S D$ & 5.18 & 3.96 & 4.72 & 3.36 & 4.53 & 5.70 & - & - \\
\hline
\end{tabular}



Table 2

Intercorrelations Among Personality Variables

\begin{tabular}{|c|c|c|c|c|c|c|c|c|c|c|}
\hline Personality Variables & 1. & 2. & 3. & 4. & 5. & 6. & 7. & 8. & 9. & 10. \\
\hline 1. Extraversion & & $.19^{* * *}$ & .09 & $-.32^{* * * *}$ & $.13^{*}$ & $.15^{* *}$ & $.19^{* *}$ & -.07 & $-.82^{* * * *}$ & $-.41^{* * * *}$ \\
\hline 2. Agreeableness & & - & $.29^{* * *}$ & .03 & $.17^{* *}$ & $-.32^{* * *}$ & $-.21^{* * * *}$ & $-.62^{* * *}$ & $-.28^{* * * *}$ & $-.19^{* *}$ \\
\hline 3.Conscientiousness & & & - & $-.15^{* *}$ & $.18^{* *}$ & $-.24^{* * *}$ & $-.16^{* * *}$ & $-.26^{* * *}$ & $-.18^{* *}$ & $-.22^{* * *}$ \\
\hline 4. Neuroticism & & & & - & -.09 & .11 & $.14^{*}$ & .05 & $.40^{* * * *}$ & $.84^{* * * *}$ \\
\hline 5. Openness & & & & & - & $.19^{* *}$ & $.18^{* * *}$ & $.17^{* *}$ & -.10 & -.06 \\
\hline 6.Machiavellianism & & & & & & - & $.59^{* * * *}$ & $.64^{* * * *}$ & .08 & $.21^{* * * *}$ \\
\hline 7. Narcissism & & & & & & & - & $.43^{* * *}$ & .04 & $.22^{* * *}$ \\
\hline 8. Psychopathy & & & & & & & & - & $.22^{* * *}$ & $.27^{* * *}$ \\
\hline 9. Social inhibition & & & & & & & & & - & $.55^{* * *}$ \\
\hline 10. Negative affectivity & & & & & & & & & & - \\
\hline
\end{tabular}

Note. ${ }^{* * *} p<.001,{ }^{* *} p<.01, \stackrel{*}{p}<<.05 . N=312$. 

Table 3

Intercorrelations Among Susceptibility to Persuasion Subscales

Susceptibility

1. Scarcity

2. Liking

3.Reciprocity

4. Commitment

5. Consensus

6. Authority
1. $2 . \quad 3$

3.4.

5 . 5

5.

6.

\begin{tabular}{|c|c|c|c|c|}
\hline $.28^{* * * * *}$ & $.18^{* *}$ & $.23^{* * * *}$ & $.31^{* * * *}$ & $.30^{* * * *}$ \\
\hline \multirow[t]{4}{*}{ - } & $.26^{* * *}$ & $.22^{* * *}$ & $.55^{* * *}$ & $.39^{* * *}$ \\
\hline & - & $.52^{* * *}$ & $.18^{* *}$ & $.34^{* * *}$ \\
\hline & & - & -.08 & $.39^{* * *}$ \\
\hline & & & - & $.49^{* * *}$ \\
\hline
\end{tabular}

Note. ${ }^{* * *} p<.001,{ }^{* *} p<.01 . N=312$ 

Table 4

Model Fit Indices for 2- through 5-Profile Solutions

\begin{tabular}{cccccc}
\hline Profiles & BIC & Adj BIC & VLMR & BLRT & Entropy \\
\hline 2 & 8593.93 & 8495.61 & .008 & $<.001$ & .80 \\
$\mathbf{3}$ & $\mathbf{8 4 1 3 . 5 7}$ & $\mathbf{8 2 8 0 . 3 6}$ & $\mathbf{. 0 3}$ & $<.001$ & $\mathbf{. 8 5}$ \\
4 & 8312.59 & 8144.50 & .08 & $<.001$ & .88 \\
5 & 8258.79 & 8055.80 & .32 & $<.001$ & .89 \\
\hline
\end{tabular}

Note. $N=312$. A combination of lowest BIC and adjusted BIC with highest number of profiles and significant $p$ values for VLMR and BLRT indicate best fit. Entropy values close to 1 indicate best fit. 

Table 5

Profile Variables: Means, Standard Errors and Mean Differences across Three Personality Profiles

\begin{tabular}{|c|c|c|c|c|c|}
\hline \multirow[b]{2}{*}{ Personality Variables } & \multirow{2}{*}{$\begin{array}{c}\text { Profile } 1 \\
\text { Malevolent } \\
(n=68)\end{array}$} & \multirow{2}{*}{$\begin{array}{c}\text { Profile } 2 \\
\text { Socially Apt } \\
\quad(n=148)\end{array}$} & \multirow{2}{*}{$\begin{array}{c}\text { Profile } 3 \\
\text { Fearful } \\
(n=96)\end{array}$} & \multicolumn{2}{|c|}{ Univariate } \\
\hline & & & & $F(2,309)$ & Partial $\eta^{2}$ \\
\hline Extraversion & $\begin{array}{c}43.85^{\mathrm{a}} \\
(.93)\end{array}$ & $\begin{array}{c}47.91^{b} \\
(.63)\end{array}$ & $\begin{array}{c}29.01^{\mathrm{c}} \\
(.78)\end{array}$ & $182.18^{* * * *}$ & .54 \\
\hline Agreeableness & $\begin{array}{c}46.78^{\mathrm{a}} \\
(.93)\end{array}$ & $\begin{array}{c}58.49^{b} \\
(.63)\end{array}$ & $\begin{array}{c}53.95^{\mathrm{c}} \\
(.78)\end{array}$ & $54.58^{* *}$ & .26 \\
\hline Conscientiousness & $\begin{array}{l}42.69^{\mathrm{a}} \\
(1.04)\end{array}$ & $\begin{array}{c}49.74^{\mathrm{b}} \\
(.70)\end{array}$ & $\begin{array}{c}45.73^{\mathrm{c}} \\
(.87)\end{array}$ & $17.34^{* * * *}$ & .10 \\
\hline Neuroticism & $\begin{array}{l}44.38^{\mathrm{a}} \\
(1.30)\end{array}$ & $\begin{array}{c}39.14^{\mathrm{b}} \\
(.88)\end{array}$ & $\begin{array}{l}50.01^{\mathrm{c}} \\
(1.10)\end{array}$ & $30.01^{* * *}$ & .16 \\
\hline Openness & $\begin{array}{c}49.52^{\mathrm{a}} \\
(.94)\end{array}$ & $\begin{array}{c}49.62^{\mathrm{a}} \\
(.64)\end{array}$ & $\begin{array}{c}48.39^{\mathrm{a}} \\
(.79)\end{array}$ & .79 & .01 \\
\hline Machiavellianism & $\begin{array}{c}18.57^{\mathrm{a}} \\
(.54)\end{array}$ & $\begin{array}{c}10.32^{\mathrm{b}} \\
(.36)\end{array}$ & $\begin{array}{c}11.45^{\mathrm{b}} \\
(.45)\end{array}$ & $84.95^{* * *}$ & .36 \\
\hline Narcissism & $\begin{array}{c}18.84^{\mathrm{a}} \\
(.55)\end{array}$ & $\begin{array}{c}11.35^{\mathrm{b}} \\
(.38)\end{array}$ & $\begin{array}{c}11.96^{\mathrm{b}} \\
(.47)\end{array}$ & $67.64^{* * *}$ & .30 \\
\hline Psychopathy & $\begin{array}{c}15.41^{\mathrm{a}} \\
(.45)\end{array}$ & $\begin{array}{l}7.78^{b} \\
(.31)\end{array}$ & $\begin{array}{c}10.21^{\mathrm{c}} \\
(.38)\end{array}$ & $97.38^{* * *}$ & .39 \\
\hline Social inhibition & $\begin{array}{c}12.66^{\mathrm{a}} \\
(.46)\end{array}$ & $\begin{array}{l}7.30^{b} \\
(.31)\end{array}$ & $\begin{array}{c}19.52^{\mathrm{c}} \\
(.39)\end{array}$ & $303.52^{* * *}$ & .66 \\
\hline Negative affectivity & $\begin{array}{c}14.86^{\mathrm{a}} \\
(.68)\end{array}$ & $\begin{array}{l}9.19^{b} \\
(.46)\end{array}$ & $\begin{array}{c}17.41^{\mathrm{c}} \\
(.57)\end{array}$ & $68.53^{* * *}$ & .31 \\
\hline
\end{tabular}

Note. Means in rows with different superscripts are significantly different at $p<.05$. ${ }^{*} p<.05,{ }^{* *} p<.001$ 

Table 6

Outcome Variables: Means, Standard Errors and Mean Differences across Three Personality Profiles

\begin{tabular}{|c|c|c|c|c|c|}
\hline \multirow[b]{2}{*}{$\begin{array}{l}\text { Susceptibility to } \\
\text { Persuasion }\end{array}$} & \multirow{2}{*}{$\begin{array}{c}\text { Profile } 1 \\
\text { Malevolent } \\
(n=68)\end{array}$} & \multirow{2}{*}{$\begin{array}{c}\text { Profile } 2 \\
\text { Socially Apt } \\
\quad(n=148)\end{array}$} & \multirow{2}{*}{$\begin{array}{c}\text { Profile } 3 \\
\text { Fearful } \\
(n=96)\end{array}$} & \multicolumn{2}{|c|}{ Univariate } \\
\hline & & & & $F(2,309)$ & Partial $\eta^{2}$ \\
\hline Scarcity & $\begin{array}{c}\mathbf{2 3 . 3 2} \mathbf{a}^{\mathrm{a}} \\
(.62)\end{array}$ & $\begin{array}{c}\mathbf{2 1 . 5 3}^{\mathrm{b}} \\
(.42)\end{array}$ & $\begin{array}{c}21.67^{\mathrm{ab}} \\
(.53)\end{array}$ & $3.07^{*}$ & .02 \\
\hline Liking & $\begin{array}{c}18.94^{\mathrm{a}} \\
(.48)\end{array}$ & $\begin{array}{c}18.45^{\mathrm{a}} \\
(.33)\end{array}$ & $\begin{array}{c}18.76^{\mathrm{a}} \\
(.41)\end{array}$ & .40 & $<.01$ \\
\hline Reciprocity & $\begin{array}{c}\mathbf{2 4 . 5 3}^{\mathrm{a}} \\
(.55)\end{array}$ & $\begin{array}{c}\mathbf{2 7 . 7 0}^{\mathbf{b}} \\
(.38)\end{array}$ & $\begin{array}{c}26.79^{\mathrm{b}} \\
(.47)\end{array}$ & $11.19^{* * * *}$ & .07 \\
\hline Commitment & $\begin{array}{c}\mathbf{1 4 . 7 9}^{\mathbf{a}} \\
(.39)\end{array}$ & $\begin{array}{c}\mathbf{1 7 . 3 3}^{\mathbf{b}} \\
(.26)\end{array}$ & $\begin{array}{c}\mathbf{1 6 . 1 4}^{\mathrm{c}} \\
(.33)\end{array}$ & $15.04^{* * * *}$ & .09 \\
\hline Consensus & $\begin{array}{c}17.32^{\mathrm{ab}} \\
(.54)\end{array}$ & $\begin{array}{c}\mathbf{1 6 . 1 6}^{\mathbf{a}} \\
(.37)\end{array}$ & $\begin{array}{c}\mathbf{1 7 . 7 9}^{\mathrm{b}} \\
(.46)\end{array}$ & $4.25^{*}$ & .03 \\
\hline Authority & $\begin{array}{c}\mathbf{2 1 . 4 3} \\
(.68)\end{array}$ & $\begin{array}{c}23.67^{\mathrm{b}} \\
(.46)\end{array}$ & $\begin{array}{c}\mathbf{2 3 . 7 1}^{\mathrm{b}} \\
(.58)\end{array}$ & $4.26^{*}$ & .03 \\
\hline
\end{tabular}

Note. Means in rows with different superscripts are significantly different at $p<.05$. ${ }^{*} p<.05,{ }^{* * *} p<.001$ 


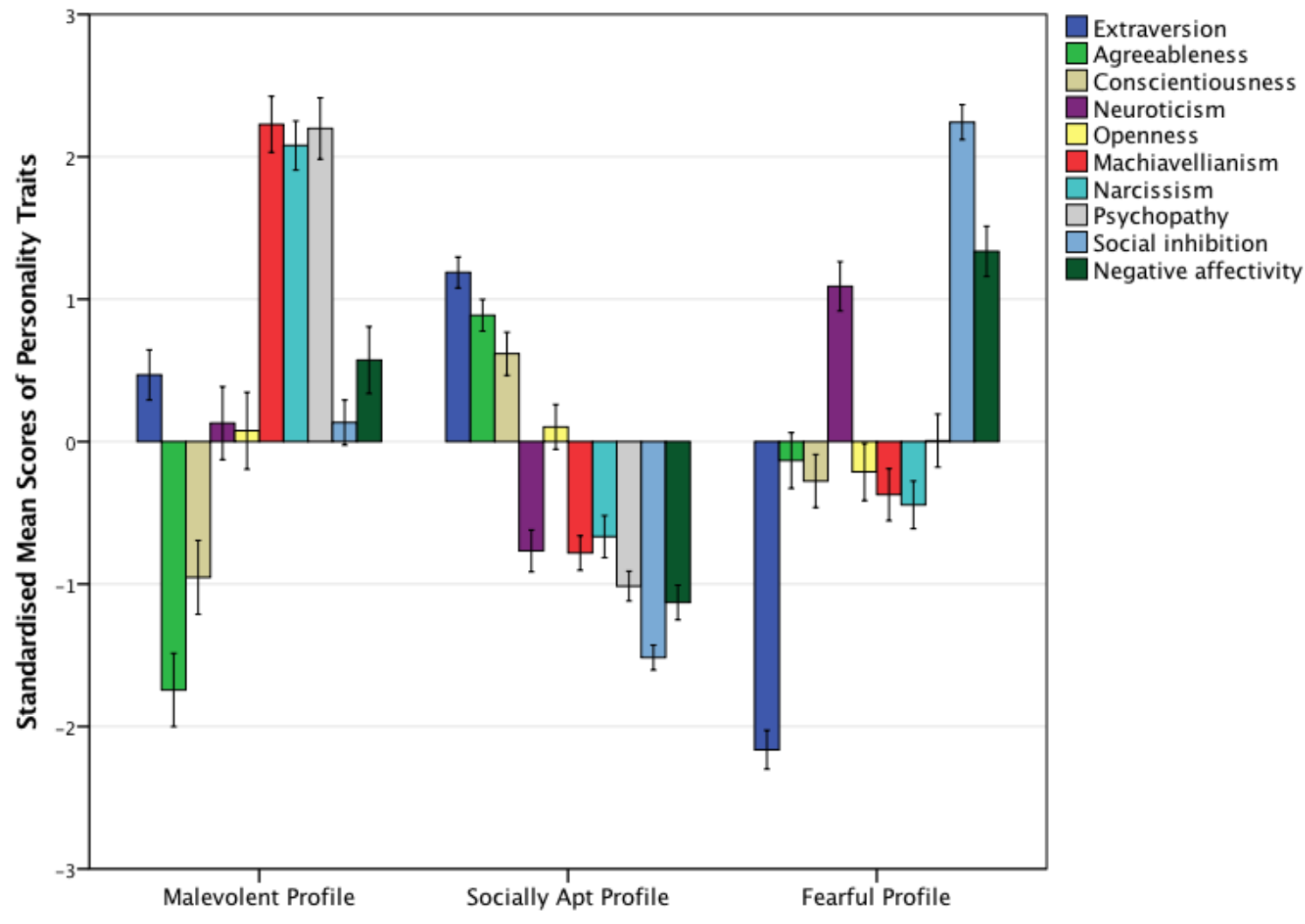

Figure 1. Standardized mean scores $(M=0, S D=1)$ of different personality characteristics across three profiles. Error bars represent standard errors (SE) \pm 1 . 